\title{
MARCO CIVIL DA INTERNET: LIMITES DA PREVISÃO LEGAL DE CONSENTIMENTO EXPRESSO E INEQUÍVOCO COMO PROTEÇÃO JURÍDICA DOS DADOS PESSOAIS NA INTERNET
}

\section{MARCO CIVIL DA INTERNET: LIMITS FROM THE EXPRESS AND UNEQUIVOCAL REQUIREMENT CONSENT AS A LEGAL PROTECTION OF PERSONAL DATA ON THE INTERNET}

\author{
${ }^{1}$ Marco Antonio Lima \\ ${ }^{2}$ Irineu Francisco Barreto Junior
}

\section{RESUMO}

Este artigo analisa os limites da previsão legal de consentimento expresso e inequívoco, para coleta, uso, armazenamento, tratamento e proteção de seus dados pessoais, previstos no Marco Civil da Internet (Lei 12.965/2014), prevista no rol de direitos e garantias dos usuários da rede mundial de computadores. Com a crescente utilização de dados pessoais oriundos da internet, para fins de análises de mercado, prospecção de tendências de investimento, consumo e orientação de campanhas publicitárias - possíveis através de recursos tecnológicos de tratamento e análise de informações -, torna-se premente a efetividade da proteção jurídica desse bem imaterial e intangível.

Palavras-chave: Sociedade da informação, Proteção de dados pessoais, Marco civil da internet

\begin{abstract}
This article examines the limits of the legal determination of express and unequivocal consent for the collection, use, storage, processing and protection of personal data as provided for in the Marco Civil da Internet (Law 12.965/2014) provided for in the list of rights and guarantees of users of the World Wide Web. With the increasing use of personal data from the Internet, for purposes of market analysis, prospecting investment trends, consumption and guidance of advertising campaigns - possible through technological resources for treatment and analysis of information - it is urgent to effectiveness the legal protection of this intangible property.
\end{abstract}

Keywords: Information society, Personal data protection, Marco civil da internet

\footnotetext{
${ }^{1}$ Mestre em Direito da Sociedade da Informação pelo Complexo Educacional das Faculdades Metropolitanas Unidas - FMU, São Paulo, (Brasil). Professor do Curso de Direito no Complexo Educacional das Faculdades Metropolitanas Unidas - FMU. E-mail: marcoantoniolima1@terra.com.br

${ }^{2}$ Doutor em Ciências Sociais pela Pontifícia Universidade Católica - PUC, São Paulo, (Brasil). Analista de Projetos Pleno da Fundação Sistema Estadual de Análise de Dados. E-mail: ifbjunio@ seade.gov.br
} 


\section{INTRODUÇÃO}

A revolução tecnológica ocorrida nos meios de comunicação deu origem a uma nova era denominada como Sociedade da Informação. A sua principal característica é a facilidade de obtenção de informações advindas de qualquer lugar do mundo em tempo quase que real, de forma jamais vista na história da humanidade. Denota-se que a informação é o centro gravitacional desta nova era, em outras palavras, é possível afirmar que ela possui valor comercial. Barreto Júnior (2015, p. 410) ao tratar do tema esclarece que:

O advento do Informacionalismo é, indubitavelmente, a principal marca
econômica da sociedade em rede. Reorganiza a produção de riqueza no
sistema econômico, no qual há uma gradativa valoração da informação como
mercadoria e fator de geração de valor econômico, o que torna a National
Association of Securities Dealers Automated Quotations (Nasdaq), bolsa de
valores das empresas tecnológicas, tão estratégica, em termos de organização
econômica, quanto a tradicional New York Stock Exchange, denominada
bolsa de Wall Street. As megacorporações informativas (Google, Facebook e
Yahoo, entre outras) acumulam vestígios de informações sobre os usuários da
Internet, tais como seus padrões de navegação, compras realizadas on-line,
preferências culturais, religiosas e ideológicas, websites de interesse, verbetes
e expressões pesquisadas nos websites de busca, entre outras, "impressões
digitais eletrônicas" que servem para estabelecer uma categorização
minuciosa de cada usuário na rede. (...) Circunscreve-se no fato de que há
inúmeros usos para esses perfis eletrônicos, tal como direcionamento de
publicidade on-line, oferta de mercadorias relacionadas ao perfil do
consumidor, além de montar cadastros de valor incomensurável sobre os
cidadãos da sociedade em rede. (BARRETO JÚNIOR (2015, p. 410)

Por esta razão, de acordo com o portal Economatica ${ }^{1}$ o valor de mercado da empresa Google Inc. é de US\$531,4 bilhões, enquanto que o da empresa Facebook é de US\$326,2 bilhões. Irrefutável a vinculação da informação com o aspecto financeiro. Marcelo Xavier de Freitas Crespo (2011, p. 38) destaca que "a informática transformouse em importantíssimo instrumento de informação e esta, por seu turno, tornou-se valioso bem econômico".

Com o crescimento exponencial da valoração de dados pessoais disponibilizados no uso da internet ou na instalação de aplicativos em smartphones, cuja finalidade é sua aplicação em análises de mercado, prospecção de tendências de 
investimento, consumo e orientação de campanhas publicitárias - cresceu nas agendas sociais e jurídicas, em escala global, a necessidade de estabelecer mecanismo que regulamentassem a coleta, uso, armazenamento, tratamento e proteção de dados pessoais. O Marco Civil da Internet (REPÚBLICA FEDERATIVA DO BRASIL. Lei 12.965/64) é a resposta do poder legislativo brasileiro aos conflitos inerentes à sociabilidade humana, surgidos com a disseminação da sociedade da informação. Expressa a resposta do legislador, entre outros aspectos advindos da convergência digital e da disseminação em escala mundial da internet, para avançar na proteção da privacidade e dos dados pessoais na rede. Destacamos, nas Disposições Preliminares e nos Princípios da lei:

Disposições Preliminares.

Art. 2-A disciplina do uso da internet no Brasil tem como fundamento o respeito à liberdade de expressão, bem como:

(...)

II - os direitos humanos, o desenvolvimento da personalidade e o exercício da cidadania em meios digitais;

Princípios.

Art. 3-A disciplina do uso da internet no Brasil tem os seguintes princípios:

I - garantia da liberdade de expressão, comunicação e manifestação de pensamento, nos termos da Constituição Federal;

II - proteção da privacidade;

III - proteção dos dados pessoais, na forma da lei;

(...)

Ainda conforme O Marco Civil da Internet, no Capítulo 2 (Dos Direitos e Garantias dos usuários), Art. $7^{\circ}$., in verbis:

Art. 7o $\mathrm{O}$ acesso à internet é essencial ao exercício da cidadania, e ao usuário são assegurados os seguintes direitos:

(...)

VI - informações claras e completas constantes dos contratos de prestação de serviços, com detalhamento sobre o regime de proteção aos registros de conexão e aos registros de acesso a aplicações de internet, bem como sobre práticas de gerenciamento da rede que possam afetar sua qualidade;

VII - não fornecimento a terceiros de seus dados pessoais, inclusive registros de conexão, e de acesso a aplicações de internet, salvo mediante consentimento livre, expresso e informado ou nas hipóteses previstas em lei;

VIII - informações claras e completas sobre coleta, uso, armazenamento, tratamento e proteção de seus dados pessoais, que somente poderão ser utilizados para finalidades que:

a) justifiquem sua coleta;

b) não sejam vedadas pela legislação; e 
c) estejam especificadas nos contratos de prestação de serviços ou em termos de uso de aplicações de internet;

IX - consentimento expresso sobre coleta, uso, armazenamento e tratamento de dados pessoais, que deverá ocorrer de forma destacada das demais cláusulas contratuais; (...).

Perante o exposto, este artigo analisa a fragilidade da determinação de obrigatoriedade de consentimento expresso e inequívoco para coleta, uso, armazenamento, tratamento e proteção de seus dados pessoais que, apesar de expressa no Marco Civil, ainda não assegura a efetiva proteção dos dados pessoais, conforme diversos relatos divulgados recentemente, sobre o uso indevido dessas informações. Para tal finalidade, o artigo trata da configuração histórica do conceito de privacidade, da privacidade como gênero, de sua proteção legal no Brasil e dos Sistemas Opt-in e Opt-out de conhecimento e livre esclarecimento para concessão de dados pessoais. Nas considerações finais será problematizada essa insuficiência da proteção normativa no intuito de assegurar a preservação dos dados pessoais na Internet.

\section{CONFIGURAÇÃO HISTÓRICA DO CONCEITO DE PRIVACIDADE}

Uma vez delineado o aspecto econômico da informação na sociedade contemporânea, não se faz necessária qualquer digressão para concluirmos sobre o valor dos dados pessoais e que, por esta razão, há uma inequívoca ameaça ao direito de privacidade, na era contemporânea. O tema privacidade permite inúmeros recortes, porém, o presente estudo está adstrito à questão da privacidade do usuário na rede mundial de computadores, com a análise de sua importância e do direito que envolve a matéria. Marcelo Cardoso Pereira (2011, p. 165) ressalta que ao se conectar à rede mundial de computadores o usuário não entra no sistema, mas, sim, passa a fazer parte integrante de toda a rede, ou seja, o seu computador passa a pertencer ao sistema interligado por máquinas, igualmente conectadas à rede das redes. Por esta razão, o usuário da rede é uma vítima em potencial de um atentado contra sua privacidade.

Não obstante, vale lembrar que a Internet não possui um dono, um guardião, ou um responsável, ao contrário ela abrange escala mundial, sendo de todos e ao mesmo 
tempo de ninguém, o que dificulta inclusive a proteção dos dados dos seus usuários. Por este ângulo, Liliana Minardi Paesani (2014, p. 37):

\begin{abstract}
A utilização dos computadores determinou uma transformação qualitativa nos efeitos decorrentes da coleta de informações. A tecnologia, com a inserção de mecanismos cada vez mais sofisticados de difusão de informações, tem contribuído para um estreitamento crescente do circuito privado, na medida em que possibilita, até a longa distância, a penetração na intimidade da pessoa.

Hoje, não é o governo que ameaça a privacidade - é o comércio pela Internet. A web transformou-se num mercado e, nesse processo, fez a privacidade passar de um direito a um commodity. O poder informático indica não só a possibilidade de acumular informações em quantidade ilimitada sobre a vida de cada indivíduo, isto é, suas condições físicas, mentais, econômicas ou suas opiniões religiosas e políticas, mas também de confrontar, agregar, rejeitar e comunicar as informações assim obtidas. (Grifos nossos). (PAESANI, 2014, p. 37)
\end{abstract}

Contudo, em que pesem as características da sociedade contemporânea, o direito à privacidade está devidamente protegido por leis, mas especificamente pelo Marco Civil da Internet, sendo necessário, no entanto, estabelecer o conceito de privacidade, para que então façamos a análise crítico jurídica deste direito.

A tutela jurídica do direito à privacidade surgiu apenas no Século XIX. De acordo com a doutrina o marco regulatório deste direito teria ocorrido em Boston (EUA), em razão da conduta da imprensa local que frequentemente publicava manchetes que destacam os atributos físicos da esposa do advogado Samuel Dennis Warren. Assim, em razão do desconforto gerado com esta situação referido advogado e seu colega Louis Dembitz Brandeis ajuizaram uma ação buscando o reconhecimento do direito de "ser deixado em paz”, em razão do direito à privacidade. Posteriormente, referidos advogados, publicaram do artigo intitulado de The Right To Privacy ${ }^{2}$, pela Harvard Law Review, em 1890:

Este artigo tornou-se referência, praticamente unânime em toda a doutrina especializada, encabeçando a lista dos artigos jurídicos norte-americanos mais citados na história, em razão do vanguardismo e ousadia ao tentar identificar na common law uma norma a fim de proteger a privacidade do cidadão.

O questionamento e o momento histórico permitiam que o debate levantado no referido ensaio exaltasse o chamado right to privacy, o qual, apenas três anos após a publicação do artigo, foi empregado em uma decisão em um Tribunal da Georgia. A face constitucional deste direito nos EUA teve reconhecimento, finalmente, sob a $14^{\mathrm{a}}$ emenda, a partir de 1965 , com o caso Griswold v. Connecticut. ${ }^{3}$ 
É importante ressaltar que o direito à privacidade, até então, não era regulado de forma autônoma, isto porque, a estrutura dos direitos fundamentais, vigentes à época, era direcionada tão somente à proteção ao direito de propriedade, sendo a privacidade regulada apenas de forma indireta nas hipóteses de violação ao direito de propriedade, ou seja, nesta estrutura o direito à privacidade (ainda que por via reflexa) era um privilégio de poucos. ${ }^{4}$

Em razão dos efeitos gerados pelo artigo publicado pelos advogados Samuel Dennis Warren e Louis Dembitz Brandeis o direito à privacidade passou regulado como tutela específica do direito personalíssimo, fundado no reconhecimento do direito de ser deixado em paz ou de ser deixado só.

A sociedade, contudo, ao longo da história não permanece estática e com o advento da Era Informacional ocorreu uma mitigação do direito de privacidade, que ao nosso ver, está ameaçada de forma jamais vista na história da humanidade, desde que foi reconhecida como direito fundamental da pessoa humana, principalmente, quando analisamos a questão de forma individuada sobre o prisma da Internet, já que lá ficam disponíveis os dados de todos os usuários conectados à rede.

Vale destacar que não são raros os casos em que hackers invadem sistemas com alto grau de segurança, como ocorreu no primeiro semestre do ano de 2015 com o Pentágono $^{5}$, nos EUA. Não obstante, há o risco constante da espionagem que pode vir de qualquer lugar, como foi a interceptação de dados feitas pelo Governo dos EUA, em detrimento de autoridades brasileiras, inclusive, da presidenta da República e de Ministros do Governo ${ }^{6}$. Desta forma, ao que nos parece quanto muito o cidadão poderá limitar as informações que ele quer que sejam tornadas públicas, ainda que em detrimento de sua própria privacidade. "Trata-se da autodeterminação informacional fundada na perspectiva de que o próprio usuário deve ter controle sobre as suas informações pessoais, autodeterminando-as." (RODOTÁ, 2015, p. 267) Nesta toada:

O desenvolvimento da informática colocou em crise o conceito de privacidade, e, a partir dos anos 80, passamos a ter um novo conceito de privacidade que corresponde ao direito que toda pessoa tem de dispor com exclusividade sobre as próprias informações mesmo quando disponíveis em banco de dados. (RODOTÁ, 2015, p. 267)

Ainda segundo Stefano Rodotá (2015, p. 267) destaca que, inicialmente, a proteção à privacidade era estática (negativa - correspondente ao que não fazer), 
enquanto que nos tempos atuais ela é dinâmica (positiva - correspondente ao controle de nossas próprias informações):

\begin{abstract}
A distinção entre o direito ao respeito da vida privada e familiar e o direito à proteção dos dados pessoais não é bizantina. O direito ao respeito da vida privada e familiar reflete, primeira e principalmente, um componente individualista: este poder basicamente consiste em impedir a interferência na vida privada e familiar de uma pessoa. Em outras palavras, é um tipo de proteção estático, negativo. Contrariamente, a proteção de dados estabelece regras sobre os mecanismos de processamento de dados e estabelece a legitimidade para tomada de medidas - i.e. é um tipo de proteção dinâmico, que segue o dado em todos os seus movimentos. Adicionalmente, a supervisão e outros poderes não são somente conferidos às pessoas interessadas (os sujeitos dos dados), mas são também entregues a uma autoridade independente (art. 8.3). A proteção não é mais deixada somente aos sujeitos dos dados, uma vez que existe órgão público permanente responsável por isso. Logo, há uma redistribuição de poderes sociais e legais se formando. É de fato o fim da linha de um longo processo evolutivo experimentado pelo conceito de privacidade - de uma definição original de ser deixado em paz, até o direito de controle sobre as informações de alguém e determinar como a esfera privada deve ser constituída. (Grifos nossos). (RODOTÁ, 2015, p. 267)
\end{abstract}

Não se pode olvidar que a mitigação ou até mesmo a supressão deste direito é uma realidade, encontrada inclusive no Poder Judiciário, neste sentido, o Egrégio Tribunal de Justiça do Estado de São Paulo no julgamento do recurso de Apelação Civil 1000914-38.2015.8.26.0223, de relatoria do Desembargador Relator Galdino Toledo Júnior, em recente julgado (01.09.2015), entendeu que as ofensas na rede social, não gerariam o dever de indenizar, pois neste ambiente preponderaria a informalidade. Ocorre que o direito à privacidade é assegurado pela Carta Magna na categoria de direito fundamental (art. 5. ${ }^{\circ} \mathrm{X}$ ), não podendo, ao nosso ver ser tolhido, sob pena de violação aos princípios básicos das garantias constitucionais e de normas de natureza infraconstitucionais.

\title{
2. PRIVACIDADE COMO GÊNERO
}

As expressões privacidade e intimidade, não são sinônimas, apesar de não raras as vezes serem usadas nesta condição. Entendemos que a privacidade compreende aos dados não sensíveis ${ }^{7}$, ao tempo em que a intimidade está ligada aos dados sensíveis das pessoas ${ }^{8}$. 
Com relação aos dados sensíveis o Anteprojeto de Lei que trata sobre a Proteção dos Dados Pessoais e tramita no Congresso Nacional, a apresenta um rol não taxativo, contemplando hipóteses de configuração:

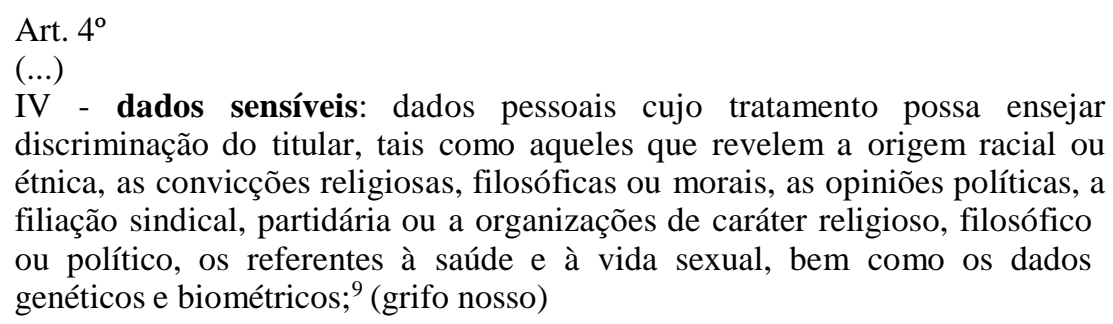
discriminação do titular, tais como aqueles que revelem a origem racial ou étnica, as convicções religiosas, filosóficas ou morais, as opiniões políticas, a filiação sindical, partidária ou a organizações de caráter religioso, filosófico ou político, os referentes à saúde e à vida sexual, bem como os dados genéticos e biométricos; ${ }^{9}$ (grifo nosso)

Portanto, a privacidade é o gênero tido como um todo, enquanto que, a intimidade é uma espécie do gênero, representando os dados sensíveis das pessoas. E este é o posicionamento adotado de forma majoritária pela doutrina: "Em sua grande maioria, consideram os juristas brasileiros que as expressões não são semelhantes, mas estão em relação de gênero e espécie, constituindo a intimidade um âmbito mais restritivo da vida privada" (BORGES, 2007, p. 21). Nesta mesma toada, Roberto Senise Lisboa (2005. p. 515) defende que são três as esferas de privacidade:

a) A pública, referente aos dados tornados públicos pelo seu titular;

b) A privada, alusiva aos dados não sensíveis da pessoa; e

c) A íntima, sobre os dados sensíveis, isto é, as convicções pessoais em geral, que guardam estrita relação com o direito à liberdade de pensamento.

\section{PROTEÇÃO LEGAL DA PRIVACIDADE}

O direito à privacidade foi regulado de forma paulatina, apenas em 1948 foi editado o primeiro documento a reconhecê-lo: Declaração Americana dos Direitos $e$ Deveres do Homem $^{10}$. Neste mesmo ano, a Assembleia Geral da Organização das Nações Unidas - ONU, reconheceu na Declaração Universal dos Direitos dos Homens $(\mathrm{DUDH})^{11}$, a privacidade como direito autônomo. No ano de 1950, em Roma, foi editada a Convenção Europeia dos Direitos do Homem $^{12}$ positivando o Direito ao Respeito pela Vida Privada e Familiar. A Convenção Americana Sobre Direitos Humanos, conhecida como Pacto de San Jose da Costa Rica ${ }^{13}$, de 22 de novembro de 1969, reconhece o direito de toda pessoa à honra e à dignidade.

Em nosso ordenamento jurídico, dentre os fundamentos da República Federativa do Brasil encontramos a dignidade da pessoa humana (art. 1. ${ }^{\circ}$, III, CF). Por 
esta razão, a interpretação de todo o sistema normativo, seja no plano Constitucional ou Infraconstitucional, deverá observar este elemento axiológico. Não se afirma aqui a existência de um direito supremo, mas de uma base mínima que deverá ser respeitada, até mesmo por vivermos em um Estado Democrático de Direito. De acordo com Celso Fiorillo (2012, p. 33) este seria o piso vital mínimo:

\begin{abstract}
Destarte, cabe reiterar que o princípio fundamental da República Federativa do Brasil que consagra a dignidade da pessoa humana deve não só ser estabelecido como 'piso' determinante de toda e qualquer política de desenvolvimento, como, necessariamente, projetar-se sobre o modo devam ser assegurados todos os demais direitos na sociedade previstos na Constituição Federal.

Daí duas conclusões importantes, com reflexo no direito constitucional brasileiro em vigor: 1) a pessoa humana passa a ser a verdadeira razão de ser de todo o sistema de direito positivo em nosso país e evidentemente do direito ambiental brasileiro; 2) a importância da pessoa humana se reafirma, no plano normativo e particularmente perante o direito ambiental brasileiro, em face de restar assegurada no plano constitucional sua dignidade como mais importante fundamento da República Federativa do Brasil, constituída que foi em Estado Democrático de Direito, a saber, uma vida com dignidade reclama desde logo a satisfação dos valores mínimos fundamentais descritos de nossa Carta Magna no art. $6^{\circ}$ (direito à educação, saúde, ao trabalho, à moradia, ao lazer, à segurança, à previdência social, à proteção à maternidade, à proteção à infância, assim como à assistência aos desamparados), verdadeiro piso vital mínimo a ser assegurado pelo Estado Democrático de Direito. (FIORILLO, 2012, p. 33).
\end{abstract}

Dentre os direitos fundamentais fixados pela Constituição Federal destacamos a proteção dada à privacidade do cidadão. Neste aspecto, nos incisos do artigo 5. , temos a expressa tutela constitucional quanto a inviolabilidade da: (i) "intimidade, a vida privada, a honra e a imagem das pessoas, assegurado o direito a indenização pelo dano material ou moral decorrente de sua violação" (inciso X); (ii) "correspondência e das comunicações telegráficas, de dados e das comunicações telefônicas, salvo, no último caso, por ordem judicial..." (inciso XII); (iii) disponibilizando o habeas data para a obtenção de dados constantes de registro ou banco de dados de entidades governamentais ou de caráter público e o direito à retificação de dados (inciso LXXII) ${ }^{14}$; Desta forma, no plano Constitucional, todo brasileiro e estrangeiro residente no Brasil tem direito a uma vida digna, com respeito à sua privacidade (gênero), pouco importando se no plano virtual ou físico.

No sistema infraconstitucional, o artigo 21 do Código Civil, por sua vez, assegura a inviolabilidade da vida privada da pessoa natural, nos seguintes termos: " $A$ vida privada da pessoa natural é inviolável, e o juiz, a requerimento do interessado, 
adotará as providências necessárias para impedir ou fazer cessar ato contrário a esta norma." Sílvio de Salvo Venosa, ao interpretar referido dispositivo legal, destaca que o direito à intimidade é intransponível, inclusive com o advento da Sociedade da Informação:

\begin{abstract}
Deve haver sempre posição firme do jurista no sentido de defender a preservação da intimidade, tantos são os ataques que modernamente. Não se pode permitir que a tecnologia, os meios de comunicação e a própria atividade do Estado invadam um dos bens mais valiosos do ser humano, que é seu direito à intimidade, seu direito de estar só ou somente na companhia dos que lhe são próximos e caros. As fotografias e imagens obtidas à socapa, de pessoas no recôndito de seu lar, em atividades especialmente privadas, são exemplos claros dessa invasão de privacidade, que deve ser coibida e pode gerar direito à indenização. Os fatos comezinhos da vida privada de cada um não devem interessar a terceiros. Tanto mais será danosa a atividade quanto mais renomada e conhecida socialmente for a vítima, mas todos, independentemente de seu nível de projeção social ou cultural, gozam da proteção. (Grifo nosso). (VENOSA, 2013, p. 47).
\end{abstract}

Em razão da ausência de um instrumento normativo para regular as operações feitas na rede mundial de computadores, foi sancionada a Lei n. ${ }^{\circ}$ 12.965/2014 - conhecida como Marco Civil da Internet, destacamos que um dos princípios de referida norma é o da privacidade do usuário da rede mundial de computadores ${ }^{15}$. Caio Cesar Carvalho Lima (2014, p.152) ao escrever sobre a privacidade assevera:

Em vista da importância do assunto, o Marco Civil estipulou a privacidade e proteção dos dados pessoais como princípios fundamentais, em seu artigo $3 .^{\circ}$, incisos II e III, trazendo como direito e garantia dos usuários a necessidade, em regra, de seu consentimento livre, expresso e informado, para a coleta, o uso, tratamento ou armazenamento dessas informações, diante das previsões, também, do artigo 7º, VIII e IX, do Marco Civil [...].” (LIMA, 2014, p.152).

Os direitos e garantias estão elencados nos artigos $7^{\circ}$ e $8^{\circ}$ da Lei 12.965/2014, cujos aspectos relacionados à privacidade serão detidamente analisados, em especial os incisos VIII e IX, que tratam sobre a política de armazenamento e coleta de dados pessoais dos usuários, os quais, de acordo com a lei, deverão anuir com a coleta dos seus dados, de forma prévia e expressa.

Nos incisos I, II e III, do artigo $7^{\circ}$ da Lei 12.965/2014, o legislador reforçou os direitos já assegurados pela Constituição Federal, que são da inviolabilidade da privacidade (gênero) e das correspondências (art. $5^{\circ}, \mathrm{X}$ e XII), a principal alteração consiste na inserção da comunicação eletrônica, que somente poderá ser violada por ordem judicial, senão vejamos: 
I - inviolabilidade da intimidade e da vida privada, sua proteção e indenização pelo dano material ou moral decorrente de sua violação;

II - inviolabilidade e sigilo do fluxo de suas comunicações pela internet, salvo por ordem judicial, na forma da lei;

III - inviolabilidade e sigilo de suas comunicações privadas armazenadas, salvo por ordem judicial;

Reconhecemos que há até uma certa desnecessidade da norma infraconstitucional reafirmar os direitos já consagrados pela Constituição Federal, entretanto com relação ao sigilo das comunicações eletrônicas, correta foi a inclusão inequívoca deste direito. Gustavo Rabay Guerra (2014, p.393), não diverge do nosso entendimento:

\begin{abstract}
Nesse contexto, grande impacto reserva o art. $7 .^{\circ}$ do Marco Civil, conquanto sublinha que as garantias gerais a respeito da privacidade encontradas na Constituição da República vigente (CRFB), em parte reproduzidas no Código Civil brasileiro, são também aplicáveis à internet. Aparentemente, os incisos I a III do predito dispositivo podem ser tidos como redundância benéfica a esses direitos. No entanto, resulta da interpretação mais atenta do inc. III do art. $7^{\circ}$ grata e oportuna normatização de uma questão até então controvertida: a restrita leitura que os tribunais brasileiros fazem da proteção de dados privados, que se limita às transmissões, como, por exemplo, uma ligação telefônica, e não àqueles dados privados que são armazenados (ou seja, na memória de um computador ou em um datacenter). (Guerra, 2014, p.393)
\end{abstract}

Como dito, a preocupação com a privacidade do usuário é inquebrantável no Marco Civil, assim, o inciso VII do artigo $7 .^{\circ}$, determina que é vedado o: "fornecimento a terceiros de seus dados pessoais, inclusive registros de conexão, e de acesso a aplicações de internet, salvo mediante consentimento livre, expresso e informado ou nas hipóteses previstas em lei;”. Desta forma, eventual dado coletado do internauta não poderá ser repassado a terceiro, salvo se houver a inequívoca autorização para tanto. Não obstante, é direito do usuário consentir prévia e inequivocamente quanto a coleta, armazenamento e tratamento dos seus dados, conforme disciplinam os incisos VIII e IX, do mesmo artigo:

VIII - informações claras e completas sobre coleta, uso, armazenamento, tratamento e proteção de seus dados pessoais, que somente poderão ser utilizados para finalidades que:

a) justifiquem sua coleta;

b) não sejam vedadas pela legislação; e

c) estejam especificadas nos contratos de prestação de serviços ou em termos de uso de aplicações de internet;

IX - consentimento expresso sobre coleta, uso, armazenamento e tratamento de dados pessoais, que deverá ocorrer de forma destacada das demais cláusulas contratuais; 
O sistema adotado pelo Marco Civil é denominado opt-in, conforme analisaremos em tópico apartado no presente estudo, porém, antes concluiremos a análise do artigo $7 .^{\circ}$, que confere ao usuário o direito de obter a exclusão definitiva dos seus dados ao término da relação entre as partes, ressalvadas as hipóteses de guarda obrigatória dos registros. Referido dispositivo é de grande valia, pois, ainda que ocorra a licitude na coleta de dados do usuário (com seu prévio e inequívoco conhecimento e expresso consentimento), não faz sentido algum que, após encerrada a relação jurídica, os dados continuem sob a guarda daquele prestador de serviços (art. 7. $, \mathrm{X}, \mathrm{MCI}$ ).

A Internet deve se basear em três pilares: informação, liberdade de expressão e a privacidade. Por esta razão, o Marco Civil da Internet em seu artigo $8^{\circ}$, determina que são nulas de pleno direito cláusula contratual que viole o direito à liberdade de expressão e à privacidade:

\footnotetext{
Art. 8o A garantia do direito à privacidade e à liberdade de expressão nas comunicações é condição para o pleno exercício do direito de acesso à internet.

Parágrafo único. São nulas de pleno direito as cláusulas contratuais que violem o disposto no caput, tais como aquelas que:

I - impliquem ofensa à inviolabilidade e ao sigilo das comunicações privadas, pela internet; ou

II - em contrato de adesão, não ofereçam como alternativa ao contratante a adoção do foro brasileiro para solução de controvérsias decorrentes de serviços prestados no Brasil. (realce original)
}

Resta claro, portanto, uma das principais preocupações do Marco Civil da Internet é com a proteção à privacidade dos usuários da rede mundial de computadores, consignando, inclusive que o Código de Defesa do Consumidor deve ser aplicado nas relações de consumo realizadas no ambiente virtual (art. $\left.7^{\circ}, \mathrm{XIII}\right)$, afastando qualquer dúvida quanto a sua incidência.

\section{DOS SISTEMAS OPT-IN E OPT-OUT}

Conforme exposto quando da análise do artigo $7 .^{\circ}$, da Lei 12965/2014, o sistema adotado pelo nosso ordenamento jurídico é denominado opt-in, neste modelo, o usuário deverá consentir de forma expressa e inequívoca, quanto ao tratamento dos seus dados pessoais. Por outro lado, o sistema opt-out (não adotado em nosso sistema) prevê que o usuário deve manifestar de forma expressa o seu interesse em sair, isto porque, o pressuposto é de concordância automática. 
O sistema opt-in está previsto em nosso ordenamento jurídico no inciso IX, do artigo $7^{\circ}$, do Marco Civil da Internet e no artigo 43, do Código de Defesa do Consumidor. Desta forma: "Por tal parâmetro normativo, repita-se, deve haver a ciência do usuário, seguida da sua escolha em permitir ou barrar a coleta, tratamento, uso e transmissão dos dados pessoais, sob pena de tal prática ser ilícita." (LIMA; BIONI, 2015, p. 268)

Com efeito, temos que a privacidade está assegurada pela Constituição Federal $\left(\operatorname{art} .5^{\circ}, \mathrm{X}\right)$, consistindo em um direito irrenunciável de acordo com a regra disposta no artigo 11 do Código Civil ${ }^{16}$, cuja a mitigação é possível nos casos autorizados em Lei. Nesta linha de raciocínio, o sistema opt-in adotado pelo Marco Civil da Internet e pelo Código de Defesa do Consumidor, permitem que o consumidor licitamente renuncie ao seu direito de privacidade, sendo vedado o consentimento presumido. Nos ensinamentos de Silvio de Salvo Venosa (2013, p. 29), encontramos a seguinte conclusão: "Evidente, porém, que nunca haverá de se admitir invasão da privacidade de alguém, utilização de sua imagem ou de seu nome sem sua expressa autorização."

Por esta razão, para considerar válido o consentimento do usuário é imprescindível que: (i) a informação sobre a coleta dos seus dados ocorra de forma adequada e clara, a permitir a sua inequívoca compreensão; (ii) consentimento prévio e expresso do usuário; (iii) nula de pleno direito a coleta realizada sem a observância dos itens "i" e "iil".

\begin{abstract}
Pode-se afirmar que o art. $8^{\circ}$ do Marco Civil dialoga com o Código de Defesa do Consumidor, ao considerar nulas de pleno direito - isto é, considerar como não escritas - todas as cláusulas contratuais que impliquem ofensa ao sigilo das comunicações privadas. Nesse sentido, será possível ler e interpretar os termos de uso e as políticas de privacidade dos sites da mesma forma como lemos os contratos de adesão nas relações de consumo. Significa dizer que deve-se considerar como não escritas as cláusulas que impliquem danos ao consumidor e à sua privacidade. (KLEE, 2015, p. 347).
\end{abstract}

Outro não é o entendimento dado por Laura Schertel Mendes: "Para que o consentimento constitua a real manifestação de vontade do consumidor de submeter os seus dados pessoais a tratamento, ele tem que atender a determinados requisitos. Assim, entende-se que o consentimento somente é válido se for expresso, livre, específico $e$ informado" (MENDES, 2015, p. 478). Acreditamos que o grande desafio existente compreende ao aperfeiçoamento prático da Lei, isto porque as Políticas de Privacidade 
dos prestadores de serviço na Internet, via de regra, longe estão de cumprirem a regra posta.

\section{CONSIDERAÇÕES FINAIS}

Apesar das determinações normativas quanto à necessidade do livre esclarecimento e consentimento como requisito para a coleta, uso, armazenamento, tratamento e proteção de dados pessoais, não é o que se observa em termos práticos. Relatos recentes comprovam a necessidade de efetivação desta proteção, que poderá advir da fase de regulamentação do Marco Civil da Internet, ou de ações judiciais que questionem essas fragilidades. Para Barreto Junior (2015, p.418), “com a crescente adesão ao uso da Internet, têm-se desenvolvido uma sensação ainda difusa, entre os seus usuários, de que não existe qualquer possibilidade de sigilo, privacidade e intimidade on-line”. Mais do que isso, o uso da rede oferece informações para um movimento em sentido reverso, no qual anúncios de produtos e ofertas de mercadorias em websites, mensagens recebidas por correio eletrônico, pop-ups e várias outras comunicações publicitárias que o usuário recebe, são orientadas pelo uso que ele próprio faz da Internet. (BARRETO JUNIOR, 2015, p.418)

Esse "direcionamento" é feito a partir de dados pessoais que o usuário da rede dissemina, de forma advertida ou inadvertida, que ocorre nas seguintes modalidades: Leitura pelo programa de navegação (browser) de cookies (arquivos temporários de navegação na internet) instalados no computador pessoal, ou outro dispositivo informático do usuário; Registro de pesquisas de preços e produtos realizada em websites; Elaboração de caracterização socioeconômica, cultural e ideológica do usuário feita em redes sociais; Registro de consultas a websites de busca, tal como o Google; Leitura convergente de aplicativos instalados em smartphones; Acompanhamento de postagens/tuites culturais, ideológicas, religiosas e outras manifestações do nas redes sociais e blogs; Convergência ente utilização de redes sociais, mecanismos de busca e ferramentas de correio eletrônico; Instalação e uso de aplicativos em dispositivos móveis. 
Os relatos a seguir ilustram os limites da proteção legal. Matéria do Jornal Folha de São Paulo, de 09 de março de 2017, revela que aplicativos de saúde, instalados em smartphones, repassam dados de usuários e geram debate ético. Segundo a reportagem: aplicativos e apetrechos eletrônicos que armazenam dados de saúde como qualidade do sono e batimentos cardíacos estão em alta e já abrem espaço para um novo ramo de pesquisas médicas com muitos dados, conhecido como big data." Conforme a reportagem, o Institute for Healthcare Informatics informa que há mais de 165 mil apps do tipo disponíveis para celular. A privacidade desses dados, no entanto, é questionável. Um estudo publicado nesta terça-feira (8) no "Jama" (revista científica da Associação Médica Americana) constatou que dados de pacientes são frequentemente vazados para anunciantes, com o objetivo de fazer publicidade direcionada, e para outras bases de dados sem o devido consentimento. O Institute for Healthcare Informatics realizou pesquisa sobre a fragilidade de dessa proteção:

\begin{abstract}
O estudo trabalhou com um universo de 211 aplicativos de saúde disponíveis para Android, todos eles voltados para pacientes com diabetes, selecionando 75 deles aleatoriamente para análise. Entre os aplicativos avaliados, $81 \%$ sequer tinham políticas de privacidade estabelecidas. Mesmo entre os $19 \%$ restantes, quase todos tinham políticas pouco transparentes e informações privadas como níveis de insulina e de glicose no sangue -além de sexo, idade, peso e, em alguns casos, geolocalização-, eram rotineiramente recolhidas e compartilhadas com terceiros. Segundo Sarah Blenner, pesquisadora do Illinois Institute of Technology Chicago-Kent College of Law e uma das autoras do estudo, o vazamento de informações pode não ter impacto prático para os pacientes, mas levanta um debate ético. Usuários colocam todo tipo de informação nesses aplicativos. Em alguns, como os de controle de sono, é possível colocar quantas horas se dorme por dia e a qualidade do sono. Em outros, como "tabelinhas virtuais", mulheres registram seu ciclo menstrual e as datas em que tiveram relações sexuais. (Jornal Folha de São Paulo, de 09 de março de 2017)
\end{abstract}

O jornalista Alex Hern, do The Guardian, resolveu se desafiar e escrever sobre, o que ele chama de "a maior mentira da internet": "li e concordo com os termos de uso". Para ele, trata-se de um "calhamaço de letras miúdas com texto muitas vezes incompreensível." O autor relata os resultados mais visíveis do seu levantamento:

O que primeiro chama a atenção, em seu relato, é a quantidade de tempo perdida com leituras maçantes. Segundo ele, toda sua leitura da semana junta - incluindo termos do Facebook, celular e até videogame - equivaleria a um livro com mais ou menos três quartos do tamanho de Moby Dick, livro do norte-americano Herman Melville que pode ser colocado de pé. Hern conta sobre como a Apple, tão conhecida pelo design e usabilidade de seus aparelhos e sistemas, é a que tem pior texto, com alguns blocos todos em letra maiúscula, impossível de ler - e, pior de tudo, desatualizado. 


\begin{abstract}
Mas a questão pode ser ainda mais complicada quando tratamos de privacidade ou direitos autorais. Alguns casos ficaram famosos, como quando foi descoberto que o Facebook vendia os dados de seus usuários para empresas. Além dele, o Twitter também diz, em seus termos (mais bem escritos, segundo Hern), que pode utilizar os textos dos twits publicados nele: "você nos outorga uma licença mundial gratuita, não exclusiva (com direito a sublicenciar) para usar, copiar, reproduzir, processar, adaptar, modificar, publicar, transmitir, exibir e distribuir esse Conteúdo em qualquer e em todos os tipos de mídia ou métodos de distribuição". ${ }^{17}$
\end{abstract}

Ele assemelha os termos de uso aos conhecidos contratos de adesão, cuja validade é frágil e objeto de inúmeros questionamentos judiciais, no Brasil, após a promulgação do Código de Defesa do Consumidor:

\begin{abstract}
Os termos de uso, conclui Hern, não são nada diferentes de um contrato que você está firmando sem saber e sem poder, ao menos, barganhar. Ainda mais quando se trata de serviços gratuitos como redes sociais — onde, como se diz, se você não está pagando, é porque não é o cliente, mas o produto... Mas termos de serviço também vêm em celulares e videogames. Hern resolveu ler o contrato de seu videogame Playstation, da Sony. Descobriu que uma das sanções que a empresa aplica para dezenas de comportamentos considerados "errados" (que vão desde piratear a simplesmente não atualizar o sistema) pode ser a inutilização completa do aparelho — seu console passa a virar um mero tijolo ao lado da televisão.
\end{abstract}

Conclui-se que, a aplicação de tecnologias como o Big Data ${ }^{18}$, análise semântica e inteligência artificial, tem exigido uma fiscalização mais atenta quanto à utilização dos dados pessoais compilados na Internet. Com a convergência tecnológica, dados que abrangem categorias como nome, sexo, idade, endereço eletrônico, CPF, rendimentos, associados ao perfil cultural, ideológico e aos padrões de consumo de cada usuário da internet, tem potencializado a captação e geração de riqueza - por intermédio direto da utilização e venda desses dados pessoais. Essa modalidade comunicacional, denominada lato sensu de publicidade on-line, tem-se tornado cada vez mais visível aos usuários da rede, percepção que tem sido disseminada, mesmo que de forma ainda difusa, entre os usuários das tecnologias informáticas. Porém, essa percepção é insuficiente para dimensionar o enorme potencial e utilização dos dados pessoais como geradores de riqueza na Internet. 


\section{REFERÊNCIAS:}

BARRETO JÚNIOR, Irineu Francisco. Proteção da Privacidade e de Dados Pessoais na Internet: O Marco Civil da Rede Examinado com Fundamento nas Teorias de Zygmunt Bauman e Manuel Castells. In: DE LUCCA, Newton; SIMÃO FILHO, Adalberto; LIMA, Cíntia Rosa Pereira de (coordenadores). Direito \& Internet III - Tomo I: Marco Civil da Internet (Lei 12.965/2014). São Paulo: Quartier Latin do Brasil, 2015.

BRASIL. Constituição da República Federativa do Brasil. Disponível em: <http://www.planalto.gov.br/ccivil_03/Constituicao/Constituicao.htm>. Acesso em: 20.03.2016.

BRASIL. Lei 8078/90 (Código de Defesa do Consumidor). Disponível em: <http://www.planalto.gov.br/ccivil_03/leis/L8078.htm>. Acesso em: 20.03.2016.

BRASIL. Lei 12.965 de 23 de abril de 2014 (Marco Civil da Internet). Disponível em: $\quad<$ http://www.planalto.gov.br/ccivil_03/_ato2011-2014/2014/lei/112965.htm> Acesso em: 12.06.2015.

BORGES, Roxana Cardoso Brasileiro. Disponibilidade dos Direitos de Personalidade e Autonomia Privada. $2^{a}$ Ed. São Paulo: Saraiva, 2007.

CASTELLS, Manuel. (traduzido por GERHARDT, Klauss Brandini; MAJER, Roneide Venâncio) A Era da Informação: Economia, Sociedade e Cultura. Fim do Milênio. v.3, São Paulo: Paz e Terra, 2012.

CRESPO, Marcelo Xavier de Freitas. Crimes Digitais. São Paulo: Saraiva, 2011.

CUKIER, Kenneth; MAYER-SCHÖNBERGER, Viktor. Big Data - Como Extrair Volume, Variedade, Velocidade e Valor da Avalanche de Informação Cotidiana. Rio de Janeiro: Campus, 2012.

FIORILlO, Celso Antonio Pacheco. Princípios do Direito Processual Ambiental. 5ed. revista, atualizada e ampliada. São Paulo: Saraiva. 2012.

GUERRA, Gustavo Rabay. Direito à Inviolabilidade e ao Sigilo das Comunicações Privadas Armazenadas: um grande salto rumo à proteção judicial da privacidade na rede. In: LEITE, George Salomão; LEMOS, Ronaldo (coordenadores). Marco Civil da Internet. São Paulo: Atlas, 2014 
KLEE, Antonia Espíndola Longoni; MARTINS, Guilherme Magalhães. A privacidade, a Proteção de Dados e dos Registros Pessoais e a Liberdade de Expressão: Algumas Reflexões sobre o Marco Civil da Internet no Brasil (Lei 12.965/2014). In: DE LUCCA, Newton; SIMÃO FILHO, Adalberto; LIMA, Cíntia Rosa Pereira de (coordenadores). Direito \& Internet III - Tomo I: Marco Civil da Internet (Lei 12.965/2014). São Paulo: Quartier Latin do Brasil, 2015.

LIMA, Caio César Carvalho. Garantia da Privacidade e Dados Pessoais à Luz do Marco Civil da Internet. In: LEITE, George Salomão; LEMOS, Ronaldo (coordenadores). Marco Civil da Internet. São Paulo: Atlas, 2014.

LIMA, Cintia Rosa Pereira; BIONI, Bruno Ricardo. Apontamentos sobre a Adjetivação do Consentimento Implementada pelo Artigo 7, Incisos VIII e IX do Marco Civil da Internet a Partir da "Human Computer Interaction" e da "Privacy By Default". In: DE LUCCA, Newton; SIMÃO FILHO, Adalberto; LIMA, Cíntia Rosa Pereira de (coordenadores). Direito \& Internet III - Tomo I: Marco Civil da Internet (Lei 12.965/2014). São Paulo: Quartier Latin do Brasil, 2015.

LIMA, Fernando Gaburri de Souza. A Boa-Fé Objetiva e seus Desdobramentos em Relação ao Dever de Informação dos Provedores de Conexão e Acesso a Aplicações da Internet. In: DE LUCCA, Newton; SIMÃO FILHO, Adalberto; LIMA, Cíntia Rosa Pereira de (coordenadores). Direito \& Internet III - Tomo I: Marco Civil da Internet (Lei 12.965/2014). São Paulo: Quartier Latin do Brasil, 2015.

LIMA, Rosa Pereira; BIONI, Bruno Ricardo. A proteção dos Dados Pessoais na Fase de Coleta: Apontamentos sobre a Adjetivação do Consentimento Implementada pelo Artigo 7, Incisos VIII e IX do Marco Civil da Internet a Partir da Human Computer Interaction e da Privacy By Default. In: DE LUCCA, Newton; SIMÃO FILHO, Adalberto; LIMA, Cíntia Rosa Pereira de (coordenadores). Direito \& Internet III Tomo I: Marco Civil da Internet (Lei 12.965/2014). São Paulo: Quartier Latin do Brasil, 2015.

LISBOA, Roberto Senise. Direito \& Internet: Aspectos Jurídicos Relevantes. 2ed. São Paulo: Quartier Latin do Brasil, 2005.

MENDES, Laura Schertell. A Tutela da Privacidade do Consumidor na Internet: Uma Análise à Luz do Marco Civil da Internet e do Código de Defesa do Consumidor. In: 
DE LUCCA, Newton; SIMÃO FILHO, Adalberto; LIMA, Cíntia Rosa Pereira de (coordenadores). Direito \& Internet III - Tomo I: Marco Civil da Internet (Lei 12.965/2014). São Paulo: Quartier Latin do Brasil, 2015.

PAESANI, Liliana Minardi. Direito e Internet: Liberdade de Informação, Privacidade e Responsabilidade Civil. $7^{\text {a }}$ Ed., São Paulo: Atlas, 2014.

PEREIRA, Marcelo Cardoso. Direito à Intimidade na Internet. Curitiba: Juruá, 2011. RODOTÀ, Stefano. (traduzido por: DONEDA, Danilo; MORAES, Maria Celina Bodin) A Vida na Sociedade da Vigilância: A privacidade hoje. Rio de Janeiro: Renovar, 2008.

VENOSA, Sílvio de Salvo. Código Civil Interpretado. 3. a ed. São Paulo: Atlas. 2013.

WARREN, Samuel Dennis; BRANDEIS, Louiz Dembetz. The Right do Privacy. Disponível em: <http://www.abolish-alimony.org/content/privacy/Right-to-privacyBrandeis-Warren-1890.pdf>. Acesso em 20.03.2016.

\footnotetext{
${ }^{1}$ Disponível em: < https://economatica.com/estudos/2016/zero160203.pdf>. Acesso em: 23.03.2016.

2 WARREN, Samuel Dennis; BRANDEIS, Louiz Dembetz. The Right do Privacy. Disponível em: <http://www.abolish-alimony.org/content/privacy/Right-to-privacy-Brandeis-Warren-1890.pdf >. Acesso em 20.03.2016.

${ }^{3}$ PEZZI, Ana Paula Jacobus. A necessidade de proteção dos dados nos arquivos de consumo: em busca da concretização do direito à privacidade. Disponível em: <http://biblioteca.asav.org.br/vinculos/tede/necessidade\%20de\%20protecao.pdf>. Acesso em 20.03.2016, p. 20.

${ }^{4}$ Ibidem. P. 22.

5 Disponível em: <http://g1.globo.com/tecnologia/noticia/2015/04/hackers-russos-invadem-rede-deinformatica-do-pentagono.html>. Acesso em: 23.03.2016.

${ }^{6}$ Disponível em: http://www1.folha.uol.com.br/mundo/2015/07/1651688-segundo-wikileaks-dilma-eaviao-presidencial-foram-espionados-pelos-eua.shtml>. Acesso em: 21.03.2016.

${ }^{7}$ Dados não sensíveis: aqueles que apesar de não serem secretos não dizem respeito ao público em geral, neste sentido, podemos citar como exemplos: o estado civil, a idade e a profissão.

${ }^{8}$ Dados sensíveis: caráter íntimo, dizem respeito somente a ela, estão voltados às próprias convicções do indivíduo e estão intimamente ligados aos seus pensamentos e crenças, como por exemplo: as convicções religiosas, os pensamentos e as convicções filosóficas

9 Disponível em: <http://www.acessoainformacao.gov.br/menu-de-apoio/recursos-passo-apasso/anteprojeto-lei-protecao-dados-pessoais.pdf/view>. Acesso em 12.10.2015.

${ }^{10}$ Art. $5^{\circ}$ : "toda pessoa tem direito à proteção da lei contra-ataques abusivos à sua honra, à sua reputação e à sua vida particular e familiar". Disponível em: <http://pfdc.pgr.mpf.mp.br/atuacao-e-conteudos-deapoio/legislacao/direitos-humanos/declar_dir_dev_homem.pdf>. Acesso em 20.03.2016.

11 Art. 12: "Ninguém será objeto de ingerências arbitrárias em sua vida privada, sua família, seu domicílio ou sua correspondência, nem a ataques à sua honra e reputação. Toda pessoa tem direito à
} 


proteção da lei contra tais interferências ou ataques." Disponível em:
<http://www.ohchr.org/EN/UDHR/Documents/UDHR_Translations/por.pdf > .Acesso em: 20.03.2016.

${ }^{12}$ Art. $8^{\circ}$ - 1 . Qualquer pessoa tem direito ao respeito da sua vida privada e familiar, do seu domicílio e da sua correspondência.

2. Não pode haver ingerência da autoridade pública no exercício deste direito senão quando esta ingerência estiver prevista na lei e constituir uma providência que, numa sociedade democrática, seja necessária para a segurança nacional, para a segurança pública, para o bem-estar económico do país, a defesa da ordem e a prevenção das infracções penais, a proteção da saúde ou da moral, ou a proteção dos direitos e das liberdades de terceiros. (grifo nosso). Disponível em: 〈http://www.echr.coe.int/Documents/Convention_POR.pdf〉. Acesso em 23.03.2016.

13 Artigo 11 - Proteção da honra e da dignidade

1. Toda pessoa tem direito ao respeito de sua honra e ao reconhecimento de sua dignidade.

2. Ninguém pode ser objeto de ingerências arbitrárias ou abusivas em sua vida privada, na de sua família, em seu domicílio ou em sua correspondência, nem de ofensas ilegais à sua honra ou reputação.

3. Toda pessoa tem direito à proteção da lei contra tais ingerências ou tais ofensas. Disponível em: <http://www.planalto.gov.br/ccivil_03/decreto/1990-1994/anexo/and678-92.pdf>. Acesso em 20.03.2016.

${ }^{14}$ Inciso LXXII - conceder-se-á habeas data:

a) para assegurar o conhecimento de informações relativas à pessoa do impetrante, constantes de registros ou bancos de dados de entidades governamentais ou de caráter público;

b) para a retificação de dados, quando não se prefira fazê-lo por processo sigiloso, judicial ou administrativo;

15 Art. 3ํ A disciplina do uso da internet no Brasil tem os seguintes princípios:

I - garantia da liberdade de expressão, comunicação e manifestação de pensamento, nos termos da Constituição Federal;

II - proteção da privacidade;

III - proteção dos dados pessoais, na forma da lei;

IV - preservação e garantia da neutralidade de rede;

V - preservação da estabilidade, segurança e funcionalidade da rede, por meio de medidas técnicas compatíveis com os padrões internacionais e pelo estímulo ao uso de boas práticas;

VI - responsabilização dos agentes de acordo com suas atividades, nos termos da lei;

VII - preservação da natureza participativa da rede;

VIII - liberdade dos modelos de negócios promovidos na internet, desde que não conflitem com os demais princípios estabelecidos nesta Lei.

Parágrafo único. Os princípios expressos nesta Lei não excluem outros previstos no ordenamento jurídico pátrio relacionados à matéria ou nos tratados internacionais em que a República Federativa do Brasil seja parte. (realce não original)

${ }^{16}$ Art. 11. Com exceção dos casos previstos em lei, os direitos de personalidade são intransmissíveis e irrenunciáveis, não podendo o seu exercício sofre limitação voluntária.

${ }^{17}$ Disponível em: <http://outraspalavras.net/blog/2015/06/18/internet-o-que-voce-assina-sem-ler/>.

Acesso em 20. Jun. 2015.

18 "Big Data é qualquer tipo de dado - estruturado ou não - como um texto, áudio, vídeo, cliques, registros e outros. Big Data é mais do que apenas uma questão de tamanho: é uma oportunidade de descobrir insights em novos tipos de dados e conteúdo, para tornar o seu negócio mais ágil." In:

CUKIER, Kenneth; MAYER-SCHÖNBERGER, Viktor. Big Data - Como Extrair Volume, Variedade, Velocidade e Valor da Avalanche de Informação Cotidiana. Rio de Janeiro: Campus, 2012. 